\title{
Evaluation of the efficacy of randomized controlled trials of sensory stimulation interventions for sleeping disturbances in patients with dementia: a systematic review
}

\author{
This article was published in the following Dove Press journal: \\ Clinical Interventions in Aging \\ 17 March 2017 \\ Number of times this article has been viewed
}

\author{
Tatiana-Danai Dimitriou' \\ Magdalini Tsolaki \\ 'Neuroscience Department, Medical \\ School, Aristotle University of \\ Thessaloniki, Thessaloniki, ${ }^{2}$ Third \\ Department of Neurology, Aristotle \\ University of Thessaloniki, Macedonia, \\ Greece
}

\begin{abstract}
Objective: The current review aims to evaluate the sensory stimulation interventions in terms of reducing sleeping disturbances in patients with dementia. The nonpharmacological interventions seem to be an efficient, inexpensive, and easy tool for family caregivers. Moreover, sleeping disorders increase caregivers' distress and may lead to hospitalization.

Methods: A systematic literature search was performed. Eleven randomized controlled trials have been found. Among these eleven trials, one referred to massage therapy and acupuncture, and the other ten studies referred to bright light therapy.

Results: The results demonstrated that there are no relevant randomized controlled trials of music therapy, aromatherapy, and multisensory environment/Snoezelen referring to sleeping disturbances. Several studies have been conducted about the effect of the bright light therapy, and there is also another study that combines massage therapy and acupuncture therapy.

Conclusion: Sensory stimulation interventions are inexpensive and practical for dementia caregivers; however, only bright light therapy seems to be useful to reduce sleeping problems in dementia. The other sensory stimulation interventions lack evidence, and there is a strong need for further research.
\end{abstract}

Keywords: sensory stimulation interventions, nonpharmacological interventions, sleeping disturbances, dementia, randomized controlled trials, review

\section{Introduction}

Dementia is a chronic, progressive, devastating disorder, which in early stages is characterized by cognitive problems. In addition, dementia influences the behavior of the patient, causing behavioral and psychological problems, also known as behavioral and psychological symptoms in dementia (BPSD). ${ }^{1}$ The most common BPSD are psychosis, aggression, depression, anxiety, euphoria, apathy, abnormal motor behavior, disinhibition, agitation, sleeping disturbances, and eating disorders. ${ }^{2}$

Sleeping disorder is a common symptom in dementia, especially in Alzheimer's disease (AD), Lewy body dementia (LBD), and Parkinson's disease dementia (PDD). Specifically, $44 \%$ of patients with dementia (PwD) suffer from sleeping disturbances. ${ }^{3}$ Sleeping problem is a very vital problem not only for the patient but also for the caregiver. It causes significant distress and precipitates institutionalization. ${ }^{4}$ The most common sleeping disorders of PwD are the difficulty in falling asleep, the patient may wander or be involved in inappropriate activities during the night, getting up during the night, waking up at night and act like it is morning, being awake too early in the
Correspondence: Tatiana-Danai Dimitriou

44 Salaminos Street, Halandri, 15232

Athens, Greece

Tel +302I 6978 II 3357

Email tt.kirxof@gmail.com 
morning, sleeping excessively during the day, and having nightmares. ${ }^{5}$ Therefore, sleeping disturbances affect sleep duration and sleep quality.

The economic impact of dementia is astounding. The annual cost is expected to surpass 1 trillion dollars in 2050, and the estimated number of PwD will reach $\sim 65.7$ million people by 2030 and 115.4 million by $2050 .{ }^{6}$ Furthermore, the pharmacological treatment of sleeping disturbances still needs further research. There have been several trials that examined the effectiveness of melatonin in sleeping problems in dementia. ${ }^{7-10}$ The trials confirm a strong evidence of melatonin in combination with a sensory stimulation intervention and bright light therapy (BLT) ${ }^{11}$ However, the effect of melatonin itself on treating sleeping disorders in dementia needs further research. Additionally, the impact of cholinesterase inhibitors (donepezil, rivastigmine, and galantamine) seems limited. ${ }^{3}$ Likewise, it is also a common phenomenon to use sedative-hypnotics and secondgeneration antipsychotics in order to treat sleeping disorders in dementia. ${ }^{12}$ However, these drugs often cause significant side effects to the patients, and therefore, they should be avoided, as possible. ${ }^{13}$ Benzodiazepines are another drug category that is used extensively to treat sleeping disorders. However, it is worth to mention that recent trials have found that benzodiazepines cause cognitive decline, disorientation, memory problems, and risk of falls. ${ }^{14}$ Therefore, it seems that there is a strong need of finding effective nonpharmacological interventions. The nonpharmacological interventions known till now can be summarized into four major categories: ${ }^{15}$ 1) cognitive/emotion-oriented interventions (reminiscence therapy, simulated presence therapy, reality orientation, validation therapy, and cognitive stimulation therapy), 2) sensory stimulation interventions (music therapy, aromatherapy, BLT, massage therapy, multisensory stimulation therapy, and acupuncture), 3) behavior management techniques (Montessori theory, low noise, decreased sensory stimulation, and caregiver's education), and 4) other psychosocial interventions (physical exercise).

Sensory stimulation is a nonpharmacological intervention category. It refers to a variety of techniques that aim to stimulate the senses and not the cognitive part of the patient. ${ }^{16}$ The notion of sensory stimulation interventions has its roots in the $1960 \mathrm{~s} .{ }^{17}$ According to the philosophy of the intervention, the senses enable patients to interact effectively with the environment and communicate better with others. ${ }^{17}$ In terms of dementia, sensory stimulation interventions in general have been found as effective and studied for reducing sleeping disturbances and among others agitation, depression, apathy, and anxiety symptoms. This was the reason that the current review examined them. However, one critical question that occurs is do all of the sensory stimulation interventions help dementia patients in their sleeping problems? The current review aims to address the following objective: to evaluate the efficacy of randomized controlled trials (RCTs) of sensory stimulation nonpharmacological interventions for sleeping disturbances in PwD.

\section{Methods}

\section{Search strategy}

Studies were extracted from MEDLINE, PubMed, Web of Knowledge, CINAHL, EMBASE, Cochrane Library, PsycINFO, LILACS, and SCOPUS. The search was controlled to find RCTs of sensory stimulation interventions for sleeping disturbances in PwD. For practical reasons, the search excluded papers written in any other language but English. For an overview of the search terms, refer to Box 1.

\section{Study selection}

The papers selected for this systematic review strictly met the following criteria: 1) were sensory stimulation interventions, 2) were RCTs, 3) were referring to sleeping disorders in dementia, and 4) were using the same diagnostic criteria of the Diagnostic and Statistical Manual of Mental Disorders, Fourth Edition (DSM-IV) and the National Institute of Neurological and Communicative Disorders and Stroke and the Alzheimer's Disease and Related Disorder Association (NINCDS-ADRDA). The titles and abstracts were evaluated for the preceding criteria. If the title and the abstract did not meet the criteria, then the articles were retrieved and screened.

\section{Data extraction}

The first reviewer extracted articles that matched the inclusion criteria. The studies were examined for their participant characteristics, content of the intervention, methodology, and outcomes. The two authors discussed about any disagreement on the extraction process.

\section{Results \\ Study characteristics}

The number of manuscripts excluded from the search were 14 studies for massage therapy, 4 studies for acupuncture,

\section{Box I Systematic literature search}

$308 \rightarrow$ potentially relevant articles: $47 \rightarrow$ exclusion articles based on abstract or full text: $36 \rightarrow$ selected articles for the review: I I 
and 5 studies for BLT. We did not find any relevant study for music therapy, aromatherapy, and multisensory therapy/ Snoezelen. Finally, we included 11 studies for all the sensory stimulation interventions that were referring to sleeping disturbances in PwD. Among these 11 trials, 1 referred to massage therapy and acupuncture and the other 10 studies referred to BLT.

\section{Participants}

A total of 760 participants were included in the studies. All of the participants were PwD in different stages. The inclusion criteria for all the studies were 1) a clear diagnosis of dementia according to DSM-IV and NINCDS-ADRDA or ICD-10, 2) to be an RCT, 3) to refer to sensory stimulation interventions, and 4) to refer to sleeping disturbances in dementia.

The smallest sample size was 13 participants ${ }^{18}$ and the larger one was $189 .{ }^{19}$ Four studies had sample sizes $<25$ participants. ${ }^{18,20-22}$ In addition, one trial stabilized the medication of their participants for 12 weeks. ${ }^{22}$ Moreover, two other trials reported no medication treatment during the BLT intervention, ${ }^{23,24}$ another study did not report its plan on medication $^{25}$ and in two other trials there were no changes in medication. ${ }^{20}$

Finally, all of the studies included patients with AD; however, some of them also included patients with vascular dementia (VaD), ${ }^{19-21,26}$ LBD, ${ }^{19,26}$ and mixed dementia. ${ }^{19,20,26}$ One study did not report the type of dementia. ${ }^{18}$ The study about massage therapy and acupuncture included patients with $\mathrm{AD}, \mathrm{VaD}$, and mixed type of dementia. ${ }^{27}$

\section{Research design and methodology}

Overall, this review included 10 RCTs about BLT and one RCT study about massage therapy and acupuncture. ${ }^{27}$ Two studies used a single-blind crossover design, ${ }^{20,21}$ four studies used a single-blind design, ${ }^{18,23-25}$ one study used a double-blind design, ${ }^{19}$ another one was an experimental study, ${ }^{22}$ another study did not give much information about its design, except the fact that the interviews were blinded and had an independent rater $^{26}$ and the other two studies were RCTs. ${ }^{27,28}$ The shortest duration was 10 days $^{25}$ and the longest was 3.5 years. ${ }^{19}$

Moreover, 7 of the 10 studies about BLT used a control group that received dim/standard light. ${ }^{18-21,23-25}$ Most of the studies used $\sim 10,000$ lux for their interventions (from 5,000 to 10,000 lux); however, one study used only 400 lux for both their experimental and control groups. ${ }^{28}$ Approximately half of the studies were conducted in the USA, ${ }^{21-25,28}$ one of them was conducted in Japan, ${ }^{20}$ one in Switzerland, ${ }^{18}$ one in the $\mathrm{UK},{ }^{26}$ one in the Netherlands, ${ }^{19}$ and another one in Spain. ${ }^{27}$
Among the 10 studies of BLT, 4 trials did not report any significant effect of BLT on the reduction of sleeping disturbances in PwD. ${ }^{23-26}$ The other six trials reported that BLT decreased nightmares and also increased sleep quality and duration. ${ }^{19-22,28}$ Likewise, most of the studies used a Bright Light box, ${ }^{20,21,23-27}$ another study used Dawn-Dusk simulator for the first time in the literature, ${ }^{18}$ another trial used the blue-green light via a cap visor22 and finally another trial used Plexiglass diffusers. ${ }^{19}$

In terms of evaluating the sleep-awake activity of the participants, some studies used wrist actigraphy. ${ }^{18-20,22,28}$ In addition, blind participants or seriously visually impaired patients were excluded from the trials in all the 10 studies.

Furthermore, in terms of risk of bias, it seemed that five studies reported low risk of bias. ${ }^{18,19,22,25,28}$ Two studies had unclear data ${ }^{20,21}$ and three studies had a high risk of bias. ${ }^{23,24,26}$ Five studies reported positive results of BLT; ${ }^{19-22,25}$ however, one study mentioned that the follow-up did not show great changes in sleeping disturbances of the patients. ${ }^{21}$ Two other trials underlined the importance of further research. ${ }^{19,26}$ However, three studies did not mention any significant improvement with BLT. ${ }^{18,23,24}$ The study about massage therapy and acupuncture mentioned positive findings. ${ }^{27}$ Table 1 shows the characteristics of the included studies.

\section{Discussion}

In this review, we aimed to provide a systematic review of the sensory stimulation interventions that seem to have an impact on sleeping disturbances of PwD. It seems that from all of the sensory stimulation interventions (music therapy, massage therapy, multisensory environment/Snoezelen, acupuncture, BLT, and aromatherapy), only three interventions (massage therapy, acupuncture, and BLT) have been studied for reducing sleeping disturbances in PwD with RCTs. The other sensory stimulation interventions have shown positive results in the reduction of agitation, aggressive behavior, apathy, and depression but have not been studied for sleeping disturbances. It seems that there is a strong need for further research.

The most efficient sensory stimulation intervention seems to be BLT. In particular, five studies reported positive results of BLT. There is also one study about massage therapy and acupuncture. BLT seems to be a promising nonpharmacological intervention for the reduction of sleeping problems. However, one crucial issue that arises is regarding the participants. First of all, 4 of the 10 studies used a small sample size ( $<25$ participants). Moreover, most of the trials included only patients with AD. This is a critical issue because other types of dementia can cause critical sleeping problems. For instance, patients who suffer from LBD and 


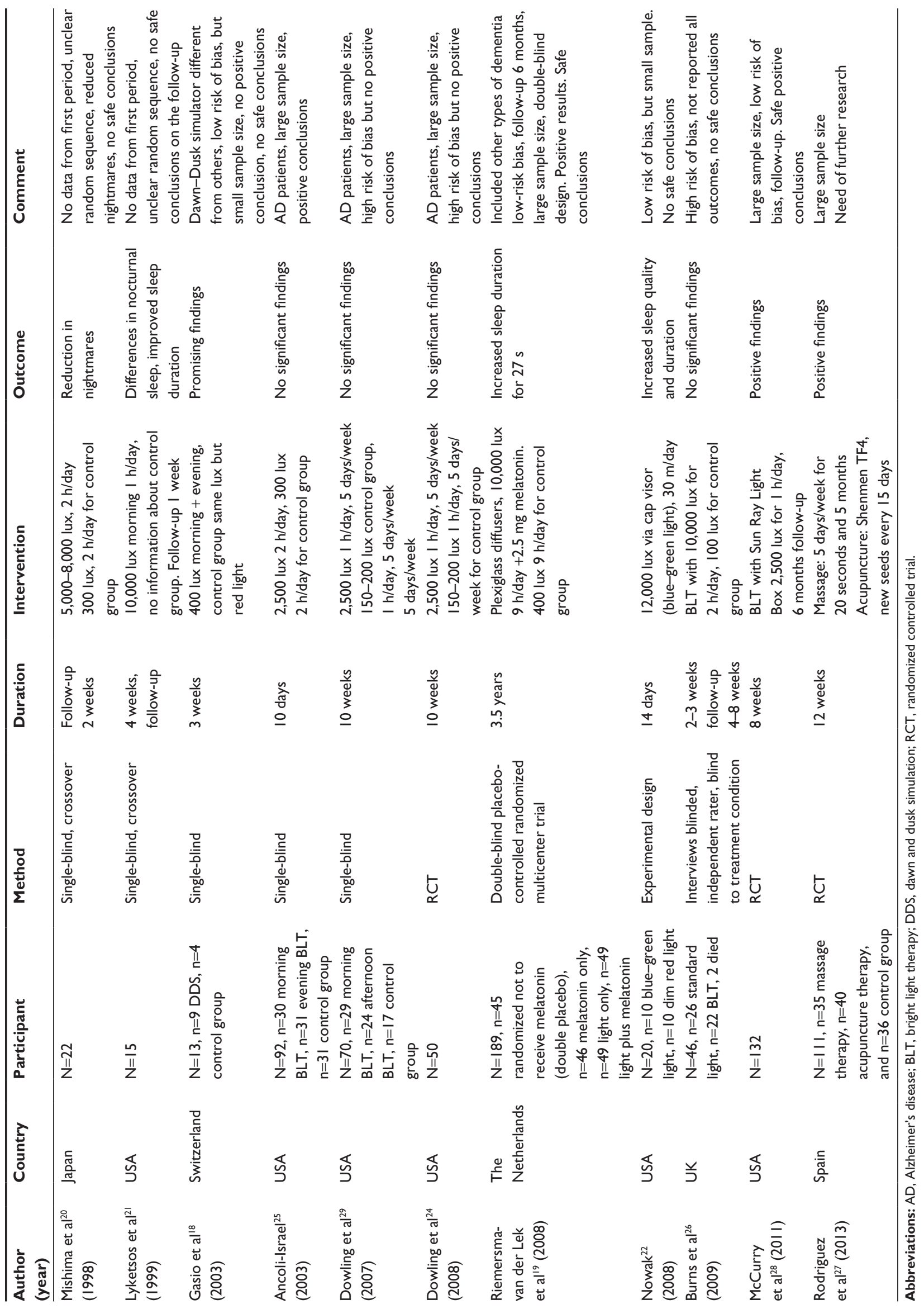


PDD experience sleeping disturbances sometimes even before their cognitive decline. Sleeping problem in dementia is a vital reason that may lead the patient to institutionalization. Therefore, it would be essential for future studies to include patients with all the different types of dementia. Also, the trials included patients with all the different stages of the disease. That means that there is heterogeneity of the severity of the sample sizes. It would be crucial to examine if BLT intervention has the same positive impact on the mild cognitive impairment (MCI) patients, on the early stages of dementia, and the more severe stages of dementia.

Likewise, the trials used different lights for the therapy and this is an interesting aspect for the future studies, as well. Nevertheless, it seems that the Dawn-Dusk simulator exposes only 400 lux of light, which compared to the others (Sun Ray light box, Bright Light box, light via a cap visor, and Plexiglass diffusers) is really limited. Moreover, another interesting question is if the BLT intervention has also a positive impact after the intervention. Furthermore, most of the participants were residents of long-term care facilities (assisted living, specialized wards, nursing homes, and wings), and only one trial included patients who lived in the community. This is actually something important because BLT intervention seems to be rather impractical for everyday use in a home place and also seems to be expensive. Maybe for the patients who still live in their homes, it would be better to find more personalized interventions that are practical and less expensive.

Finally, it is also worth to mention some other limitations of the trials; one study did not give information about the duration of the program, and therefore its results cannot be safe. The duration of the intervention also seemed to be short (just a few weeks) in most studies. Only one trial, which also used a double-blind design and 189 participants, lasted for 3.5 years. In terms of massage therapy and acupuncture, the results seem to be promising. However, acupuncture therapy can be used only under the supervision of an expert in acupuncture, and therefore it is also not practical for patients who live in the community. However, massage therapy is an easy intervention that can be used by the family caregivers. Nevertheless, there is a strong need for further research.

\section{Disclosure}

The authors report no conflicts of interest in this work.

\section{References}

1. Soril LJJ, Leggett LE, Lorenzetti DL, et al. Effective use of the built environment to manage behavioural and psychological symptoms of dementia: a systematic review. PLoS One. 2014;9(12):e115425.
2. Sampson EL, White N, Lord K, Leurent B, Vickerstaffa SS, Jonesa L. Pain, agitation, and behavioural problems in people with dementia admitted to general hospital wards: a longitudinal cohort study. Pain. 2015;156(4):675-683.

3. Urrestarazu E, Iriarte J. Clinical management of sleep disturbances in Alzheimer's disease: current and emerging strategies. Nat Sci Sleep. 2016;8:21-33

4. Xiao LD, Wang J, He G-P, De Bellis A, Verbeeck J, Kyriazopoulos H Family caregiver challenges in dementia care in Australia and China: a critical perspective. BMC Geriatr. 2014;14:6.

5. Cummings JL, Mega M, Gray K, Rosenber-Thompson S, Carusi DA, Gornbein J. The Neuropsychiatric Inventory. Neurology. 1994;44(12): 2308.

6. Alzheimer's Association. 2015 Alzheimer's disease facts and figures. Alzheimers Dement. 2015;11(3):332-384.

7. Burke TM, Markwald RR, Chinoy ED. Combination of light and melatonin time cues for phase advancing the human circadian clock. Sleep. 2013;36(11):1617-1624.

8. Jenwitheesuk A, Nopparat C, Mukda S, Wongchitrat P, Govitrapong P Melatonin regulates aging and neurodegeneration through energy metabolism, epigenetics, autophagy and circadian rhythm pathways. Int J Mol Sci. 2014;15(9):16848-16884.

9. Wade AG, Farmer M, Harari G, et al. Add-on prolonged-release melatonin for cognitive function and sleep in mild to moderate Alzheimer's disease: a 6-month, randomized, placebo-controlled, multicenter trial. Clin Interv Aging. 2014;9:947-961.

10. Gehrman PR, Connor DJ, Martin JL, Schochat T, Corey-Bloom J, AncoliIsrael S. Melatonin fails to improve sleep or agitation in a double-blind randomized placebo-controlled trial of institutionalized patients with Alzheimer's disease. Am J Geriatr Psychiatry. 2009;17(2):166-169.

11. Bonmati-Carrion MA, Arguelles-Prieto R, Martinez-Madrid MJ, et al. Protecting the melatonin rhythm through circadian healthy light exposure. Int J Mol Sci. 2014;15(12):23448-23500.

12. Marston L, Nazareth I, Petersen I, Walters K, Osborn DPJ. Prescribing of antipsychotics in UK primary care: a cohort study. BMJ Open. 2014; 4(12): e006135.

13. Gareri P, Segura-García C, Manfredi VGL, et al. Use of atypical antipsychotics in the elderly: a clinical review. Clin Interv Aging. 2014;9: 1363-1373.

14. Zhong G, Wang Y, Zhang Y, Zhao Y. Association between benzodiazepine use and dementia: a meta-analysis. PLoS One. 2015;10(5): e0127836.

15. O'Neil ME, Freeman M, Christensen V, Telerant R, Addleman A, Kansagara D. Systematic Evidence Review of Non-pharmacological Interventions for Behavioural Symptoms of Dementia. Washington, DC: Department of Veterans Affairs; 2011.

16. Lykkeslet E, Gjengedal E, Skrondal T, Storjord MB. Sensory stimulation - a way of creating mutual relations in dementia care. Int J Qual Stud Health Well-being. 2014;9:10.

17. Ayres J. Sensory Integration and Learning Disorders. Los Angeles, CA: Western Psychological Services; 1972.

18. Gasio PF, Krauchi K, Cajochen C, et al. Dawn-dusk simulation light therapy of disturbed circadian rest-activity cycles in demented elderly. Exp Gerontol. 2003;38(1-2):207-216.

19. Riemersma-van der Lek RF, Swaab DF, Twisk J, Hol EM, Hoogendijk WJG, Van Someren EJW. Effect of bright light and melatonin on cognitive and noncognitive function in elderly residents of group care facilities: a randomized controlled trial. JAMA. 2008;299(22): 2642-2655.

20. Mishima K, Hishikawa Y, Okawa M. Randomized, dim light controlled, crossover test of morning bright light therapy for rest-activity rhythm disorders in patients with vascular dementia and dementia of Alzheimer's type. Chronobiol Int. 1998;15(6):647-654.

21. Lyketsos CG, Veiel LL, Baker A, Steele C. A randomized, controlled trial of bright light therapy for agitated behaviors in dementia patients residing in long-term care. Int J Geriatr Psychiatry. 1999;14(7): $520-525$. 
22. Nowak L. The effect of timed blue-green light on sleep-wake patterns in women with Alzheimer's disease. Diss Abstr Int B. 2008;69(6-B): $1-154$.

23. Downling GA, Graf C, Hubbard EM, Luxenberg JS. Light treatment for neuropsychiatric behaviours in Alzheimer's disease. West J Nurs Res. 2007;29(8):961-975.

24. Dowling GA, Burr RL, Van Someren EJ, et al. Melatonin and brightlight treatment for rest-activity disruption in institutionalized patients with Alzheimer's disease. J Am Geriatr Soc. 2008;56(2):239-246.

25. Ancoli-Israel S, Gehrman P, Martin JL, et al. Increased light exposure consolidates sleep and strengthens circadian rhythms in severe Alzheimer's disease patients. Behav Sleep Med. 2003;1(1):22-36.

26. Burns HA, Allen H, Tomenson B, Duignan D, Byrne J. Bright light therapy for agitation in dementia: a randomized controlled trial. Int Psychogeriatr. 2009;21(4):711-721.
27. Rodriguez-Mansilla J, Gonzales-Lopez-Arza MV, Varela-Donoso E, Montanero-Fernandez J, Jimenez-Palomares M, Garrido-Ardila EM. Ear therapy and massage therapy in the elderly with dementia: a pilot study. J Tradit Chin Med. 2013;33(4):461-467.

28. McCurry SM, Pike KC, Vitiello MV, Logsdon RG, Larson EB, Teri L. Increasing walking and bright light exposure to improve sleep in community-dwelling persons with Alzheimer's disease: results of a randomized, controlled trial. J Am Geriatr Soc. 2011;59(8):1393-1402.

29. Dowling GA, Graf C, Hubbard EM, Luxenberg JS. Light Treatment for Neuropsychiatric Behaviors in Alzeimer's Disease. West J Nurs Res. 2007;29(8):961-975.
Clinical Interventions in Aging

\section{Publish your work in this journal}

Clinical Interventions in Aging is an international, peer-reviewed journal focusing on evidence-based reports on the value or lack thereof of treatments intended to prevent or delay the onset of maladaptive correlates of aging in human beings. This journal is indexed on PubMed Central, MedLine,

\section{Dovepress}

CAS, Scopus and the Elsevier Bibliographic databases. The manuscript management system is completely online and includes a very quick and fair peer-review system, which is all easy to use. Visit http://www.dovepress. com/testimonials.php to read real quotes from published authors. 